EPJ manuscript No.

(will be inserted by the editor)

\title{
Current status and future developments of the ion beam facility at the Centre of Micro-Analysis of Materials in Madrid
}

\author{
A. Redondo-Cubero ${ }^{1,2 a}$, M.J.G. Borge ${ }^{1,3}$, N. Gordillo ${ }^{1,2}$, P.C. Gutiérrez ${ }^{1,4}$, J. Olivares ${ }^{1,5}$, R. Pérez Casero ${ }^{1,2}$, and \\ M.D. Ynsa ${ }^{1,2}$ \\ 1 Centro de Microanálisis de Materiales, Universidad Autónoma de Madrid, 28049 Madrid, Spain \\ 2 Departamento de Física Aplicada, Universidad Autónoma de Madrid, 28049 Madrid, Spain \\ 3 Instituto de Estructura de la Materia, Consejo Superior de Investigaciones Científicas, 28006 Madrid, Spain \\ 4 ALBA Synchrotron Light Source (CELLS-ALBA), 08290 Cerdanyola del Vallès, Barcelona, Spain \\ ${ }^{5}$ Instituto de óptica, Consejo Superior de Investigaciones Científicas, 28006 Madrid, Spain
}

Received: date / Revised version: date

\begin{abstract}
We report on the current status of the ion beam laboratory of the Centre of Micro-Analysis of Materials at the Autonomous University of Madrid. The $5 \mathrm{MV}$ accelerator facility provides $\mathrm{MeV}$ ion beams of any stable element. Six main beam lines are under operation, allowing the analysis and modification of materials through ion beam methods. Although the most demanded ions are $\mathrm{H}$ and $\mathrm{He}$ for standard Rutherford backscattering spectrometry and particle-induced X-ray emission experiments, many other analytical techniques and specific set-ups are available for users. The facility especially highlights for the use of high-energy heavy ions and microbeams, with important applications in material science, optics and electronics, biology, cultural heritage, and astrophysics. Ongoing upgrades of the facility are oriented to improve the quality of the service for external users and to face new scientific and technological challenges in areas such as advanced materials, space, energy and health.
\end{abstract}

PACS. 29.17. $+\mathrm{w}$ Electrostatic, collective, and linear accelerators - 79.20.Rf Atomic, molecular, and ion beam impact and interactions with surfaces - 81.70.-q Methods of materials testing and analysis - 81.20.-n Methods of materials synthesis and materials processing

\section{Introduction}

There are more than 24,000 particle accelerators worldwide, mainly devoted to industrial processes and medical applications, but also for scientific research [1]. This figure includes unique and extraordinary big machines such as the Large Hadron Collider at CERN (attaining energies of TeV), and also numerous and small machines such as portable $\mathrm{X}$-ray equipments (with energies of few keV). Medium particle accelerator facilities, typically generating MeV particles, lie in an intermediate regime. They are not so extended as compact or commercial systems, but they are also not so rare as large synchrotrons or colliders. Indeed, according to the IAEA database, there are 163 of these facilities containing electrostatic accelerators (distributed over 50 countries) [2]. These facilities play an important role in research activities for many disciplines, because they provide beam time to hundreds of scientists. Moreover, networks of these accelerator laboratories help through transnational access, facilitating the use of diverse techniques and the local contact with experts.

One of the most extended uses of these accelerator facilities is the modification and analysis of materials using ion beams. On the one hand, ions can be implanted as foreign atoms for doping, controlling both the depth and the fluence [3], which is one of the most demanded applications, especially for semiconductor materials and microelectronics. Additionally, $\mathrm{MeV}$ ions can be used to induce radiation damage [4], sputtering [5], or mixing [3]. Taking advantage of this, other important processes such as nanofabrication, patterning, phase transformation, radiation-enhanced diffusion, slicing and amorphization are achievable. This set of applications is commonly known as ion beam modification of materials (IBMM).

On the other hand, ion beam techniques can provide valuable information about the structure, the nature and the composition of materials, allowing non-destructive depth profiling in many cases. Among this set of powerful well-

\footnotetext{
a Corresponding author: andres.redondo@uam.es
} 
established techniques Rutherford backscattering spectrometry (RBS), elastic recoil detection analysis (ERDA), particle induced X-ray emission (PIXE), and nuclear reaction analysis (NRA, with the particular case of particle induced gamma-ray emission or PIGE) are likely the most popular ones. However, these techniques are complemented by other more specific methods such as ion channelling (typically combined with RBS), ionoluminescence (IL), ion-beam induced current (IBIC) or scanning transmission ion microscopy (STIM). These methods are known as ion beam analysis (IBA) techniques and comprehensive reviews of them can be found in references [6,7]. Quite remarkably, several of these techniques can be applied simultaneously to extract complementary information in an approach called totalIBA [8]. Recent reports have demonstrated the power of total-IBA experiments [9], which can reduce the uncertainty budget up to $2 \%$ in some cases [10]. As a result of these capabilities, which ensure an accurate characterization of the elemental composition of samples with good resolution and mass selectivity, the scientists that benefit from them belong to multiple disciplines: material science, biology, geology, environmental sciences, forensics, archaeology and cultural heritage, astrophysics, radiological protection, etc. [11].

In order to make the ion beam techniques more accessible to the Iberian, as well as the European scientific community, the Centre of Micro-Analysis of Materials (CMAM) began to operate in 2002 at the Autonomous University of Madrid (Spain). Initially, it was equipped with a $5 \mathrm{MV}$ tandem accelerator and one multi-purpose beam line. However, the ion beam laboratory experienced several upgrades and developments since then, regarding the ion sources, the accelerator, the beam lines and the experimental stations. As a consequence, the collection of available techniques and experiments has increased considerably. In the last decade, CMAM has supplied around 12,000 hours of beam time, allocating more than 3,000 scientific proposals from both internal and external users.

In this paper we present the current status of the ion beam facility at CMAM, describing the main experimental systems open to users. We pay special attention to the more singular characteristics in terms of technical and scientific resources, such as the use of heavy ion beams and the internal/external microbeams. Finally, we also mention some of the expected developments and scientific prospects.

\section{Technical description}

\subsection{The ion accelerator}

CMAM is equipped with a $5 \mathrm{MV}$ tandem linear accelerator fabricated by High Voltage Engineering (HVE). This machine was designed with two main advantages over previous Tandetron accelerators: 1) terminal voltage was extended up to $5 \mathrm{MV}$ (it was limited to $3 \mathrm{MV}$ in previous models), and 2) it incorporated a coaxial Cockcroft-Walton high voltage generator [12]. The terminal voltage was originally calibrated using 11 different nuclear reactions [13]. After 11 years of operation, during March 2013, the accelerator tank was opened for the first time to replace faulty diodes (562 out of 2200). Consequently, the terminal voltage was recalibrated, finding a very small deviation from the original value (less than $0.3 \%$ ) [14].

The available ion sources are a duoplasmatron source (model HVE-358) for light ions (mainly $\mathrm{H}$ and He), and a negative sputter ion source (model HVE-860C) for heavy elements. These sources were upgraded in 2010, replacing the original thermoleak valves by mass flow controllers, allowing a faster and more precise control of the gas flow. Both sources allow the generation of almost any stable element up to $\mathrm{Pb}$, although statistically the most demanded ions at CMAM are $\mathrm{H}(41.8 \%), \mathrm{He}(25.4 \%)$, Fe (6.1\%), F(4.5\%), and $\mathrm{Br}(4.3 \%)$. Other representative ions are Si, C, $\mathrm{B}, \mathrm{I}, \mathrm{Cl}$, and $\mathrm{Au}$, which add up to an additional $12.8 \%$ of beam time. Occasionally, isotopes such as ${ }^{3} \mathrm{He},{ }^{57} \mathrm{Fe}$, and ${ }^{15} \mathrm{~N}$ are also produced for specific experiments.

\subsection{The beam lines and techniques}

Figure 1 shows the sketch of the accelerator hall of CMAM with the six current operational beam lines, identified as: standard, internal microbeam, time-of-flight (TOF), implantation, external microbeam, and nuclear physics, respectively. These beam lines allow a plethora of IBA and IBMM experiments. Next we summarize the main characteristics of these beam lines as well as the accessible techniques.

- Standard: this is a multi-purpose beam line placed at the $30^{\circ}$ port of the switching magnet. The experimental station is devoted to RBS, ERDA, PIXE, NRA and, more occasionally, IL. The experiments can be carried out in random or channelling geometries thanks to a 3 -axis goniometer with an accuracy of $0.01^{\circ}$. The beam current is measured by means of a Faraday cup placed before the experimental chamber and the beam size is controlled with two collimating slits. The analysis chamber is pumped to high vacuum and the sample holder is monitored with a small video camera. Two silicon barrier particle detectors (12 keV resolution) are used for ion collection: a fixed detector located at $170^{\circ}$ scattering angle and a movable detector with a set of foils and slits located in front of it (for ERDA and NRA). A silicon drift X-ray detector (Ketec Axas-A model, with $140 \mathrm{eV}$ resolution) is located at $135^{\circ}$ 

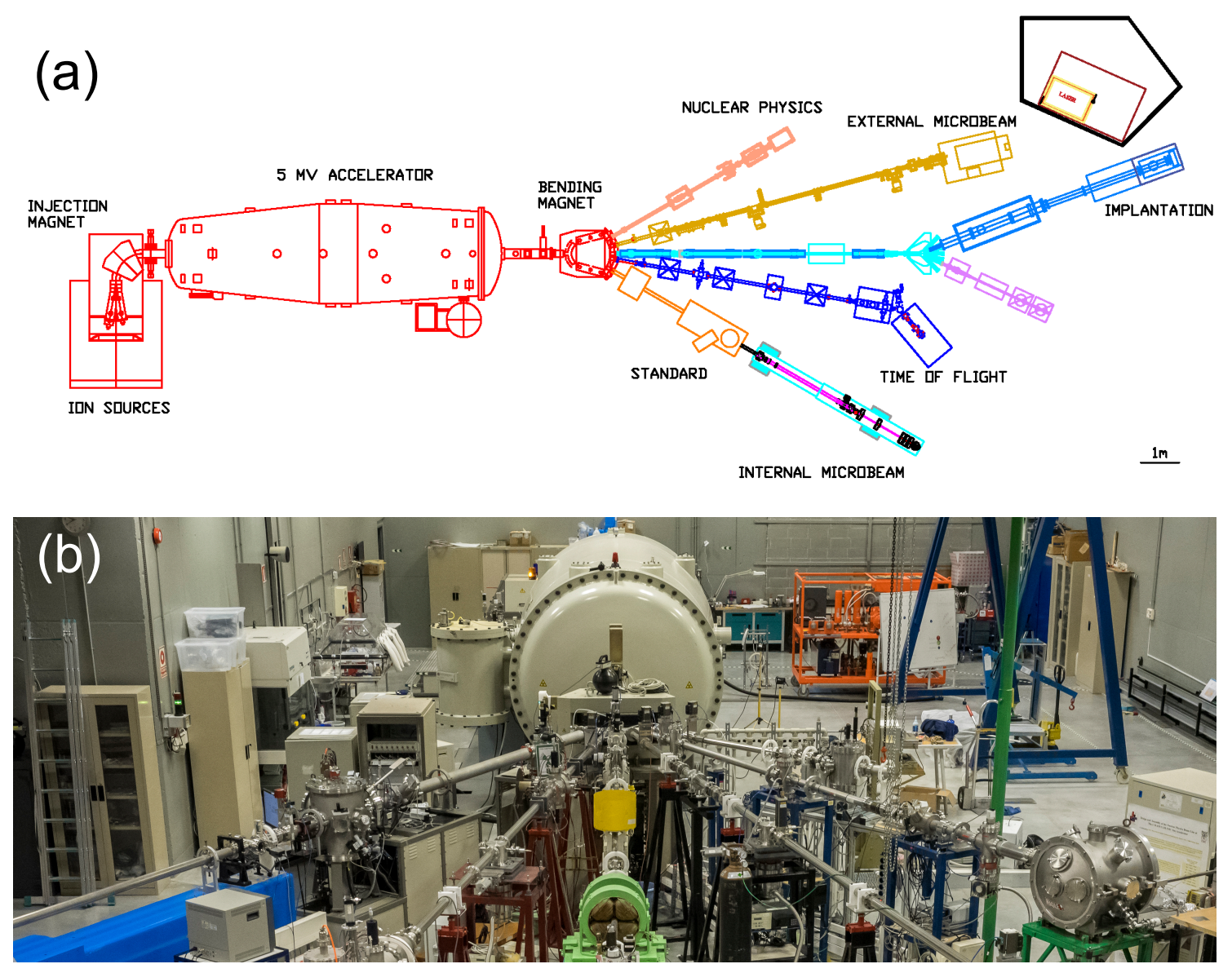

Fig. 1. (a) Sketch of the accelerator hall of CMAM with the main beam lines under operation. Note the scale legend at the bottom right. (b) Panoramic view of the accelerator and the beam lines.

scattering angle for PIXE experiments. In addition, a reverse-electrode Ge detector (Canberra GR3520 model) is used for gamma-ray detection in PIGE experiments. A non-permanent set-up of optical and infrared cameras and view-ports can be attached to the vacuum chamber in order to perform IL measurements. Ion dose is measured by a current integrator to an usual maximum precision of $0.1 \mathrm{nC}$. Recently, a new four-channel acquisition system based on an ultra-fast multiparameter multichannel analyser has been developed and implemented to improve the data collection. Due to the versatility of this station and the possibility of combining different techniques, the Standard beam line is the most suitable to perform total-IBA experiments under high vacuum conditions.

- Internal microbeam: this line is an extension of the Standard beam line that allows the focussing of a wide range of ion beams, from protons (up to $10 \mathrm{MeV}$ ) to heavy ions such as $\mathrm{B}, \mathrm{O}$, or $\mathrm{Si}$ (with tens of $\mathrm{MeV}$ ). The line was originally designed at the Micro-Analytical Research Centre (Melbourne). The beam collimation is carried out with two precise sets of micrometric X-Y slits: motorized object slits (built by TB Fischer) and manual collimator slits (manufactured at Croatia). A set of five quadrupole lenses, which optically resembles the CSIRO-GEMOC system $[15,16]$, is used to focus the beam. The configuration of these lenses is conditioned by the magnetic rigidity of the beam [17]. A $2 \mathrm{MeV}$ proton beam can be focused routinely with spatial resolutions of $2 \mu \mathrm{m} \times 2 \mu \mathrm{m}$ and currents higher than $1 \mathrm{nA}$, while heavy ions can easily reach a spot size of about $5 \mu \mathrm{m} \times 3 \mu \mathrm{m}$ with about 500 pA current. The focused beam is scanned over the sample with a magnetic deflector. Two positional stages can be used to hold the samples: a manual XYZ manipulator (McAllister MA1006) covers $150 \mathrm{~mm}$ vertically and 25 $\mathrm{mm}$ in $\mathrm{X}$ and $\mathrm{Z}$ directions, and a piezoelectric XYZ positioning stage (MechOnics MS30), which travels $60 \mathrm{~mm}$ in one direction and $30 \mathrm{~mm}$ in other two directions, with a positioning accuracy better than $100 \mathrm{~nm}$. An optical microscope is used to control the beam-sample alignment. The analysis chamber is equipped with a surface barrier Si detector for RBS, a X-ray detector for PIXE and a photodiode (placed behind the sample) for STIM analysis. 
- Time-of-flight: this is a line specifically designed for heavy ion ERDA-TOF experiments and, thus, placed at the $10^{\circ}$ port of the switching magnet. The experimental station has a 3 -axis goniometer to hold the samples and a TOF telescope installed at $40^{\circ}$ scattering angle with a collimator of $4 \mathrm{~mm}$ diameter in front of it. The telescope, under ultra-high vacuum conditions, is equipped with two carbon foil stations that allow the time signal detection with a resolution of $83 \mathrm{ps}$. The TOF stations are separated $420 \mathrm{~mm}$ and based on the Jyväskylä design [18]. The thicknesses of the carbon foils, supplied by AFC Metals, are $150 \mathrm{~nm}\left(33 \mu \mathrm{g} / \mathrm{cm}^{2}\right)$ and $50 \mathrm{~nm}\left(11 \mu \mathrm{g} / \mathrm{cm}^{2}\right)$, respectively. The electronics system for time gating includes a micro-channel plate, a fast preamplifier and constant fraction discriminator, a time-to-amplitude converter, an analog-to-digital converter and a multiparameter analyzer. The particle energy is detected using a Si detector placed $964 \mathrm{~mm}$ away from the sample, with an active area of 300 $\mathrm{mm}^{2}$ and a resolution of $14 \mathrm{keV}$. The digitalized time and energy signals and their corresponding time stamps for coincidence measurements are recorded using a multi-parameter acquisition unit (MPA3 from Fastcom). The beam current is monitored in real time thanks to a transmission Faraday cup operating at $10 \mathrm{~Hz}$ and placed before the experimental chamber.

- Implantation: this line is placed at the $-20^{\circ}$ port of the second switching magnet, connected to the $0^{\circ}$ port of the accelerator. This station allows performing homogeneous irradiation over large areas, up to $100 \times 100 \mathrm{~mm}$, even for the most extreme case of $10 \mathrm{MeV} \mathrm{H}^{+}$, thanks to a fast electrostatic beam raster (operating at $\mathrm{kHz}$ ) provided by HVE. The irradiation chamber is electrically isolated, and designed for ultra-high vacuum conditions. The load-lock is compatible with the use of 3-inch wafers. The fluence is controlled by measuring the beam current in two different ways. On the one hand, the system incorporates a Faraday cup located before the vacuum valve. On the other hand, a combination of four Faraday cups, located after the vacuum valve and immediately before the irradiation chamber can be used. The chamber contains a cryostat/furnace that allows modifying the heating and cooling ramps in order to control the sample temperature during the irradiations. The temperature can be varied from $-196{ }^{\circ} \mathrm{C}$ (liquid nitrogen cooling) up to $600{ }^{\circ} \mathrm{C}$. The sample holder can be tilted in the $\pm 90^{\circ}$ range with respect to the beam axis, allowing the in-situ characterization. This holder is made of copper to favour a uniform temperature gradient. Additionally, the beam line is provided with an InfraTec VarioCAM thermographic camera, to monitor the temperature distribution during the irradiation. Several optical techniques for in-situ measurements are available, including reflectance, transmittance and ellipsometry, all in the broad range VIS-UV. Recently, a large macro-external beam has been developed by means of using thin foils in apertures engraved at the back flange of the irradiation chamber. This set-up is capable to generate a broad beam $(30 \times 1 \mathrm{~mm})$ of heavy ions into the air. Quite remarkably, this beam line was designed to allow simultaneous irradiation with a femtosecond pulsed laser (Spectra Physics Solstice ACE model, regenerative amplifier). The laser delivers $100 \mathrm{fs}$ pulses of $6 \mathrm{~mJ} / \mathrm{pulse}$, at $1 \mathrm{kHz}$ repetition rate and $800 \mathrm{~nm}$ wavelength. An additional external wavelength conversion module is available to generate pulses at 400 or $266 \mathrm{~nm}$ wavelengths, as desired. The laser beam is directed towards the implantation chamber through a silica window.

- External microbeam: this beam line is placed at the $-15^{\circ}$ port of the switching magnet and it is one of the oldest under operation at CMAM [19]. The main characteristic of this line is the capability to carry out in-air measurements, including RBS, PIXE, PIGE, and IL, with a very small beam spot. The beam is extracted from the vacuum line to the air through a thin foil, which typically consists of a $0.2 \mu \mathrm{m} \mathrm{Si}_{3} \mathrm{~N}_{4}$ film. The spot size is controlled with a Ta collimator with a $1 \mathrm{~mm}$ diameter hole, two manually controlled micrometric X-Y slits and two quadrupole lenses (Oxford Microbeams Ltd.). The spot size varies from $1 \mathrm{~mm}$ to $50 \mu \mathrm{m}$ depending on the ion beam (around $100 \mu \mathrm{m}$ diameter in regular operation). Emitted X-rays are collected via two $\mathrm{Si}(\mathrm{Li})$ detectors located at $\pm 135^{\circ}$ scattering angles. The first one is used for the detection of low energy X-rays with a resolution of $130 \mathrm{eV}$ and an active area of $10 \mathrm{~mm}^{2}$. The second detector is employed for high energy X-ray detection. It has different absorbers (used to suppress the $\mathrm{K}_{\alpha}$ lines of desired elements), an active area of $80 \mathrm{~mm}^{2}$ and a final resolution of $150 \mathrm{eV}$. A He stream is applied around the sample to remove the air atmosphere and optimize the detection in the range of 1 to $12 \mathrm{keV}$. Emitted $\gamma$-rays are collected with HPGe and/or lanthanum bromide detectors. Backscattering particles are collected with a Si implanted blind detector (in a He flow) positioned in Cornell geometry. Emitted light is transmitted by a quartz fibre to an Ocean Optics QE-6500 spectrometer. The acquisition system allows the simultaneous acquisition of all the spectra and the motorized remote control of the sample position in XYZ directions (fabricated by RLS, Slovenia).

- Nuclear physics: this line is placed at the $-30^{\circ}$ port of the switching magnet, and it is fully equipped by the Nuclear Physics group of IEM-CSIC. Its main activity is the study of relevant nuclear reactions for astrophysics, typically those with excited states of certain nuclei near the particle threshold. The nuclei and the states of interest are populated in low energy reactions, and studied by particle and gamma detection. The reactions of interest have, in general, extremely low cross sections. Considering the required flexibility and the constraint due to Rutherford scattering, the end of the beam line is equipped with a big versatile reaction chamber. The chamber contains 
several mounting points for different type of set-ups, depending on the specific experiment. All set-ups share a design able to avoid the very strong signal from Rutherford scattering that would mask the reaction channel of interest. Besides, the detector set-ups are easily interchangeable. For charged particle detection at forward angles, a setup of $14 \mathrm{Si}$ detectors of $5 \times 5 \mathrm{~cm}^{2}$, each divided into 4 subdetectors of $6.25 \mathrm{~cm}^{2}$ [20], is mounted conforming one quarter of a $15 \mathrm{~cm}$ radius sphere. At backward angles, a more tight set-up of three double sided Si strip detectors is placed, covering from $85^{\circ}$ to $170^{\circ}$, with an angular resolution of $3^{\circ}$. Different types of gamma detection systems can be added via flanges in various directions. The segmentation of the detectors leads to a huge amount of electronic channels (200). Integrated electronics of ultimate technology is being used for read-out. The signals are, in case of scintillators and Ge detectors, digitized at the source (Mesytec MDPP-16 module), while for Si detectors a multiplexed highly integrated analogue system is used (Mesytec MDI-2 module). All units are controlled and data transported by a VME controller to personal computer via USB3 connection with a sustainable event rate of 1 $\mathrm{MHz}$ with negligible deadtime.

As an example of the studies of astrophysical relevance carried out in this beam line, we can mention the case of the cross section of the ${ }^{3} \mathrm{He}\left({ }^{4} \mathrm{He}, \gamma\right){ }^{7}$ Be between 1 and $3 \mathrm{MeV}$ energies [21]. This was analysed through the activation method, which consists on the detection of the delayed $478 \mathrm{keV} \gamma$-ray from the first excited state in ${ }^{7} \mathrm{Li}$ after the ${ }^{7}$ Be electron capture decay. Further, the excited states in ${ }^{12} \mathrm{C}$ were explored using the ${ }^{10} \mathrm{~B}\left({ }^{3} \mathrm{He}\right.$,p $\left.\alpha \alpha \alpha\right)$ reaction, in order to obtain better understanding of the triple alpha process as well as to study $\alpha$ clustering in light nuclei [22]. Other reaction presently under study is the ${ }^{19} \mathrm{~F}(\mathrm{p}, \alpha \gamma){ }^{16} \mathrm{O}$ reaction, which contains information about the radiative capture of $\alpha$ on ${ }^{12} \mathrm{C}$; of great importance for nuclear astrophysics due to its major role in determining the $\mathrm{C}$ to $\mathrm{O}$ ratio during He burning in stars.

\section{Highlights of the ion beam facility}

\subsection{High-energy heavy ions}

As it was mentioned before, $\mathrm{H}$ and He represent more than $67 \%$ of the beam time at CMAM. This is due to the high demand of RBS and PIXE experiments, which is also common in other ion beam facilities. However, for specific studies the use of complementary ERDA measurements with heavy ions is also required [23,24]. In particular, very heavy ions such as ${ }^{127} \mathrm{I}$ or ${ }^{197} \mathrm{Au}$ are used when both light and heavy elements need to be detected with good sensitivity [25]. ERDA-TOF is suitable for such conditions because it can identify the recoils without overlapping signals and with isotope resolution (in some cases). At CMAM, the ERDA-TOF beam line was designed to maximize the current for these heavy ions and, thus, to assure good statistics under those conditions.

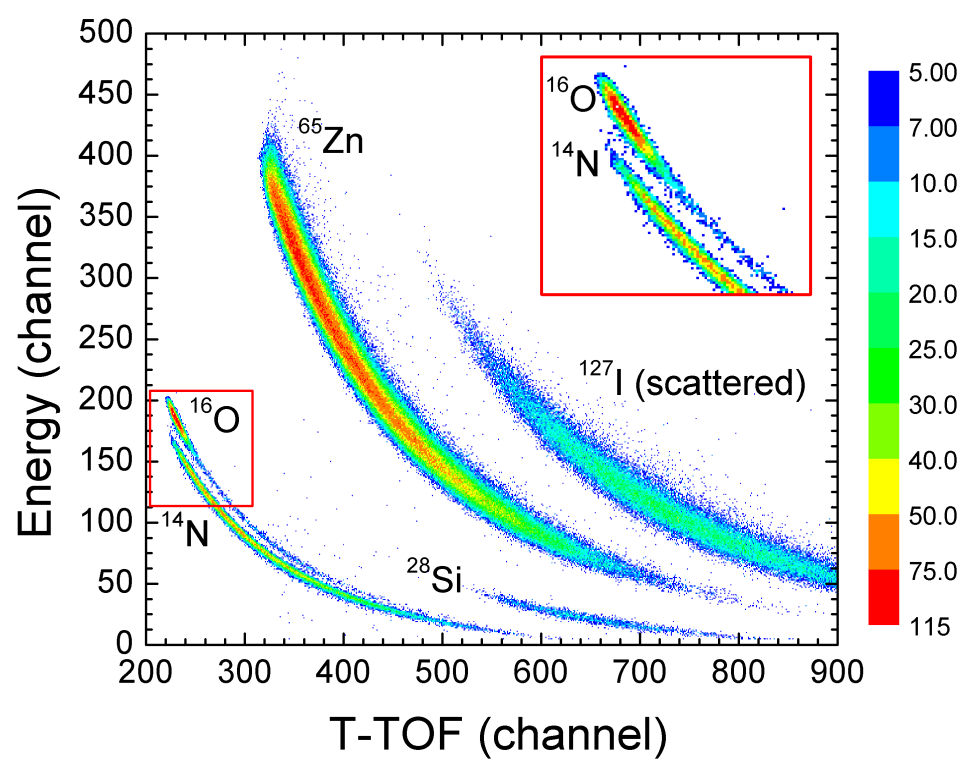

Fig. 2. ERDA-TOF spectrum of a zinc nitride sample analyzed with $30 \mathrm{MeV} \mathrm{I}^{5+}$. The sample was exposed to air during 1 week and $\mathrm{N}$ is progressively replaced by $\mathrm{O}$ in the film. This transformation is visible thanks to the separated signals of both elements and the good depth resolution at the surface (inset). The colour scale represents the yield in counts. 
Some representative studies carried out with this method have been the analysis of $\mathrm{Cr} / \mathrm{Si}$ interfaces [26], the characterization of BCN films [27] or the compositional determination of metastable ZnON layers [28, 29]. Figure 2 shows an example of this later case when using a $30 \mathrm{MeV} \mathrm{I}^{5+}$ beam. The sample under analysis is a zinc nitride layer exposed to air during one week. Due to the reaction with the water vapour present in the atmosphere, the composition of the layer changes, incorporating $\mathrm{O}$ and losing $\mathrm{N}$. This effect can be unambiguously quantified with ERDA-TOF measurements due to the detection of all the elements present in the film. Moreover, due to the high energy of the ions, the interface with the silicon substrate is also visible [28].

Apart from the use in ERDA experiments, other non-conventional applications have been also explored at CMAM. In particular, as a result of the interest in new IBA methods such as heavy ion PIXE, CMAM participated in a IAEA coordinated project to determine the cross sections of some heavy elements, particularly $\mathrm{C}$ and Si with energies below $1 \mathrm{MeV} / \mathrm{u}$ [30]. IL is other technique that can be exploited with the simultaneous irradiation of heavy ions, and its benefits for the determination of damage were reported in silica and quartz [31]. More recently, STIM analysis with heavy ions started to be used for the density of thin samples too.

Besides IBA, heavy ions are also demanded for irradiation and implantation. In particular, swift heavy ions (SHI) are a powerful tool to modify the physical, chemical, and structural properties of the materials, opening up a whole range of technological applications and research topics. SHI are particles with energies between few MeV/u up to 100 $\mathrm{MeV} / \mathrm{u}$ that exhibit a very high electronic energy density.

This range of energies is particularly suitable for the ion accelerator at CMAM (Fig. 3a) and, thus, there is an extensive collection of studies on this topic: the magnetic properties of graphite [32], the effect of Coulomb explosion for molecular ions [33], the amorphization, structural changes and the optical properties of $\mathrm{LiNbO}_{3}[34-37]$ and $\mathrm{SiO}_{2}$ [38-40], the influence of an external magnetic field on the damage in $\mathrm{Fe}_{90} \mathrm{Cr}_{10}$ [41] and $\mathrm{Fe}_{85} \mathrm{Cr}_{15}$ alloys [42], the ion-induced elongation of $\mathrm{Ag}$ nanoparticles embedded in silica [43], and the improvement in electrical conductivity of $\mathrm{LiTaO}_{3}$ and $\mathrm{LiNbO}_{3}$ crystals [44]. The scientific and technological interest of diamond has been also a point of attention for the researchers at CMAM. Using homogenous large implanted areas $\left(6 \times 6 \mathrm{~mm}^{2}\right)$, the single-crystal diamond amorphization [45] and the swelling effect [46] produced by irradiation with SHI have been analysed. Focused MeV carbon and boron ion beams have been also implanted to determine their effects in single crystals of diamond under different irradiation energies and fluences and to try to identify diamond graphitization threshold [47-50].
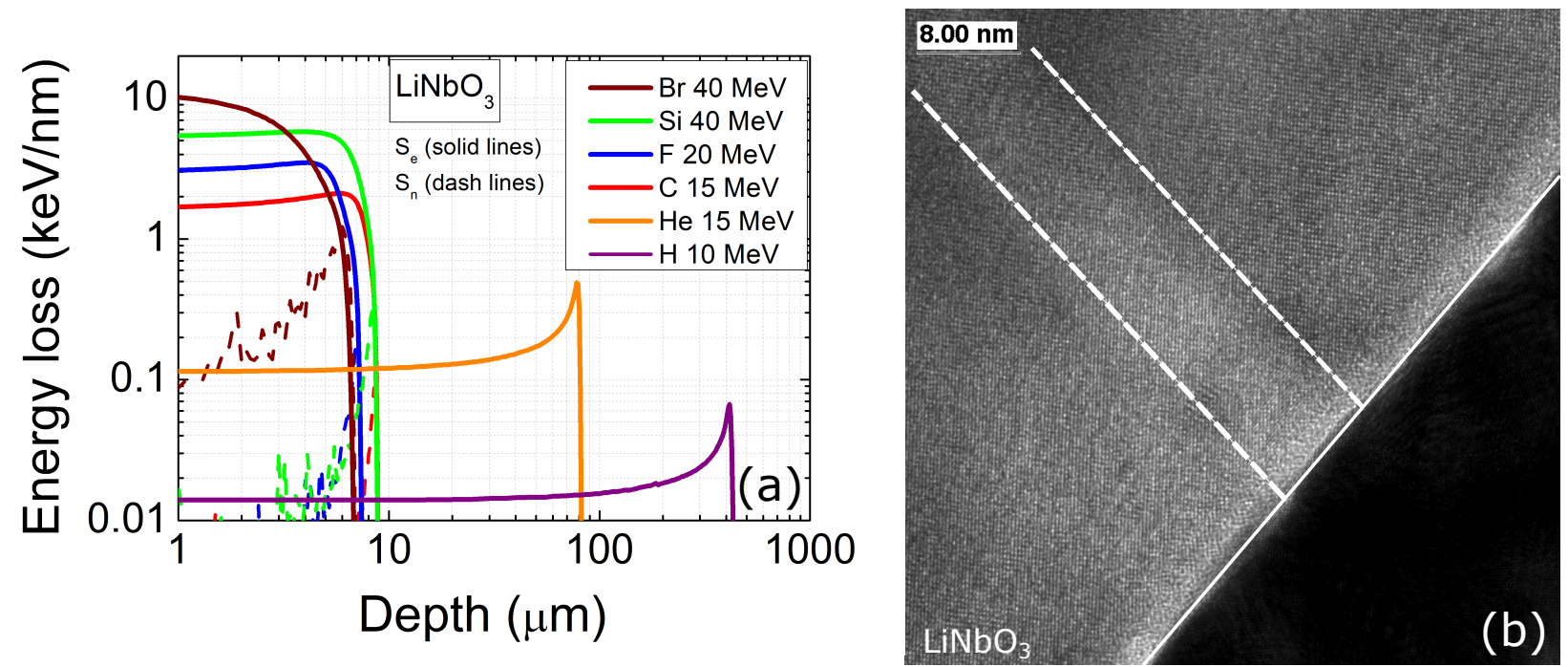

Fig. 3. (a) Range of electronic and nuclear energy loss in $\mathrm{LiNbO}_{3}$ for the maximum ion energies available at CMAM. (b) Transmission electron microscope image of an ion track produced by irradiation with $\mathrm{SHI}$ in $\mathrm{LiNbO}_{3}$ at $\mathrm{CMAM}$.

The SHI has been also used for the fabrication of different structures of technological interest, such as patterned surfaces, optical waveguides, and nanotracks (Fig. 3b). Patterned surfaces combining porous and bulk Si were attained to modify the interaction between biological cells and the substrates, an approach that proved to be successful with textured surfaces at micro- and nanoscale levels [51,52]. Buried optical waveguides for optical applications can be produced thanks to the high energy available with SHI, since the maximum electronic stopping power is localized few microns below the surface. This route has been fruitfully used at CMAM in many relevant photonic materials: lithium niobate [53-55] and other materials such as $\mathrm{KGd}\left(\mathrm{WO}_{4}\right)_{2}[56,57], \mathrm{KY}\left(\mathrm{WO}_{4}\right)_{2}[58,59], \mathrm{LiTaO}_{3}$ [60] and $\mathrm{SiO}{ }_{2}$ [61]. Along with these studies, the CMAM researchers have also a wide experience in the production of nanotracks generated by 
SHI impacts [62-64]. The applications of this ion-track technology go from fission-fragment dosimetry, to molecular sieves, and to a variety of electronic and magnetic devices.

\subsection{Internal and external microbeams}

Apart from the use of high-energy heavy ions, another remarkable characteristic of CMAM is the supply of microbeams, since two of the operative beam lines are devoted to this activities, which covers both IBA and IBMM. The use of microbeams is essential for some specific applications, in which the sample size is very small or a lateral compositional characterization is required.

Regarding the internal microbeam different PIXE, RBS, STIM and NRA studies have been carried out for the analysis of biological tissues [65], microelectronic devices [66] and diamond samples [17]. Figure 4 shows a representative example of the microscopic resolution achieved in the case of $\mathrm{Ca}, \mathrm{Mn}$ and $\mathrm{Fe}$ quantitative elemental maps for a flower stigma and the beginning of a style.
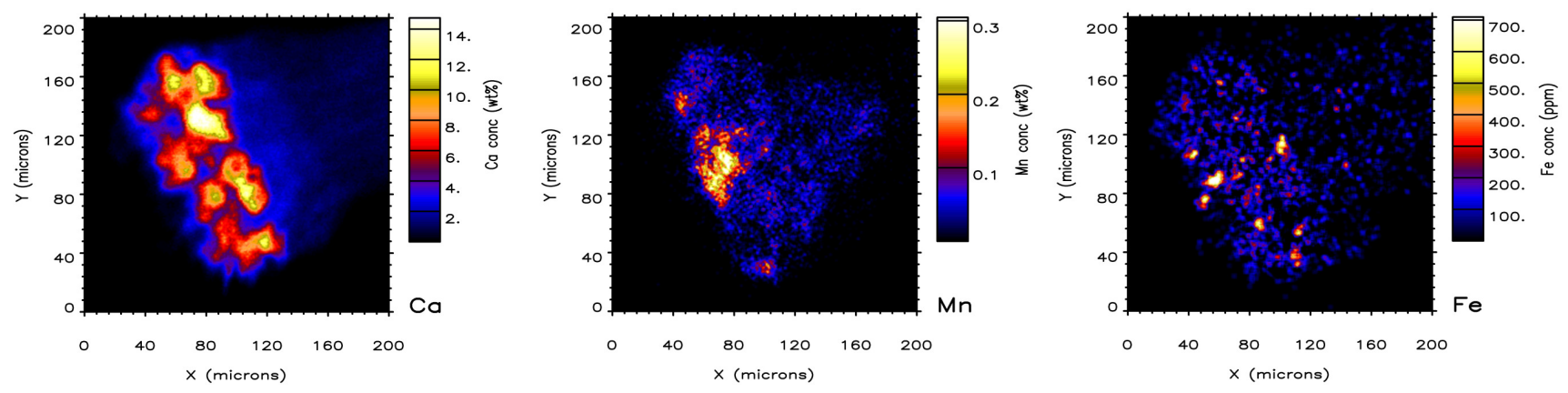

Fig. 4. PIXE quantitative elemental maps $\mathrm{Ca}, \mathrm{Mn}$ and Fe (scan dimension $200 \mu \mathrm{m} \times 200 \mu \mathrm{m}$ ) in a flower stigma and the beginning of a style.

The internal microprobe stands out because of the high beam currents (few nA) for focused proton beams. This facilitates the use of nuclear reactions where cross sections are not very high. One particular example of this is the case of the ${ }^{11} \mathrm{~B}(\mathrm{p}, \alpha)^{8} \mathrm{Be}$ nuclear reaction at $\mathrm{E}_{p}=670 \mathrm{keV}$, used to get high spatial resolution maps of B-implanted diamond samples [17]. This reaction has a high Q-value (8.59 MeV for $\alpha_{0}$ and $5.68 \mathrm{MeV}$ for $\left.\alpha_{1}\right)$ and thus is almost free of overlapping signals. Therefore, the analytical sensitivity depends exclusively on the proton beam current, spectrum acquisition time and particle-detector solid angle. The high current achieved with focused proton beams is an advantage that improves the sensitivity of $\mathrm{B}$ detection in this case.

The other aspect that highlights in the use of the internal microbeam at CMAM is the focusing of high-energy ion beams. Choosing the correct quadrupolar configuration, the range of accessible beam energies for focusing is quite broad. As a matter of fact, ions such as B, C, N, O, Si and $\mathrm{Cl}$ have been successfully focused at CMAM. Generally, the beam sizes are about $5 \times 5 \mu \mathrm{m}^{2}$ with beam currents of several hundreds of $\mathrm{pA}$, although for the more prolific ions, e.g. oxygen, beam sizes close to $1 \times 1 \mu \mathrm{m}^{2}$ have been achieved. Figure 5 shows the RBS map of a Cu grid using a focused 8.4 $\mathrm{MeV} \mathrm{N}^{3+}$ beam. From the analytical point of view, the availability of focused MeV heavy ions opens the possibility of implementing IBIC and ERDA techniques, rarely used in the microprobes. In addition, high-quality STIM images can be obtained with such heavy ions. Note that the areal density resolution of STIM images significantly increases with the ion mass, since the ion energy loss increases faster than the energy straggle. This kind of studies is starting to be applied at CMAM.

Focused ion microbeams have been also used to modify materials and fabricate nanostructures such as Si microchannels [67]. However, during the recent years, most of the implantation work with focused ion beams was targeted to the analysis of the effects produced in diamond with B and C beams [47-50]. These analysis respond to the technological interest of diamond and the possibility of changing its properties by ion-beam induced defects. The main point under investigation is the recrystallization of diamond upon annealing, since it is known that graphitization processes can occur for different defect densities, i.e., it depends on the energy and ion selected. So far, the effect of $9 \mathrm{MeV} \mathrm{C}$ [49] and $8 \mathrm{MeV} \mathrm{B}$ [50] irradiations have been studied with different results and graphitization thresholds. More studies are currently being carried out to shed more light on this topic.

For those situations in which IBA cannot be carried out in vacuum conditions, the external microprobe at CMAM offers excellent analytical capabilities. Indeed, this beam line highlights for the extensive characterization of objects belonging to the cultural heritage, i.e., for art and archaeometry [68]. This is a research field that has been highly 


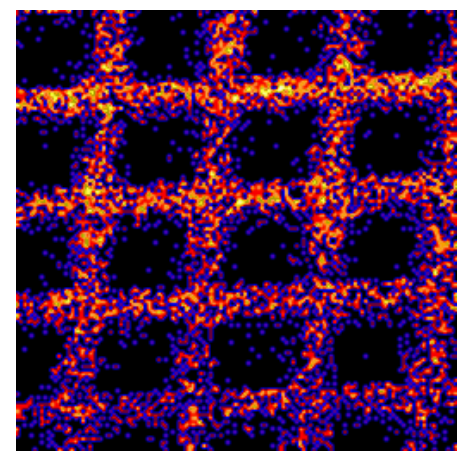

Fig. 5. RBS map of a 1000 mesh $\mathrm{Cu}$ grid (6 $\mu \mathrm{m}$ bar and $19 \mu \mathrm{m}$ hole) obtained with a focused $8.4 \mathrm{MeV} \mathrm{N}^{3+}$ beam.

developed in the last decades and that includes, not only compositional information of the samples, but the use of these data for the identification of the materials, fabrication technologies used in the antiquity, the origin, or the verification of authenticity, as well as the detection of restorations and surface alterations.

The versatility of the non-invasive and non-destructive set-up at the external microbeam allows the analysis of a variety of materials, such as metal alloys, ceramics, glass, gems, ink drawings, etc. Moreover, considering that artworks are usually made of different materials and exhibit complex shapes, external beams in combination with different IBA techniques are suitable for a complete characterization of this kind of materials.

In this sense, CMAM has participated in the characterization of numerous items, fragments and collections; some of them highly renowned, such as the pre-Colombian gold "Quimbaya Treasure" [69,70] and the "Costa Rica collection" (from the Museo de América of Madrid), the visigothic treasure "Torredonjimeno" [71] or the ink drawings of Luca Cambiaso [72] (from Musei di Strada Nuova and Museo del Prado).
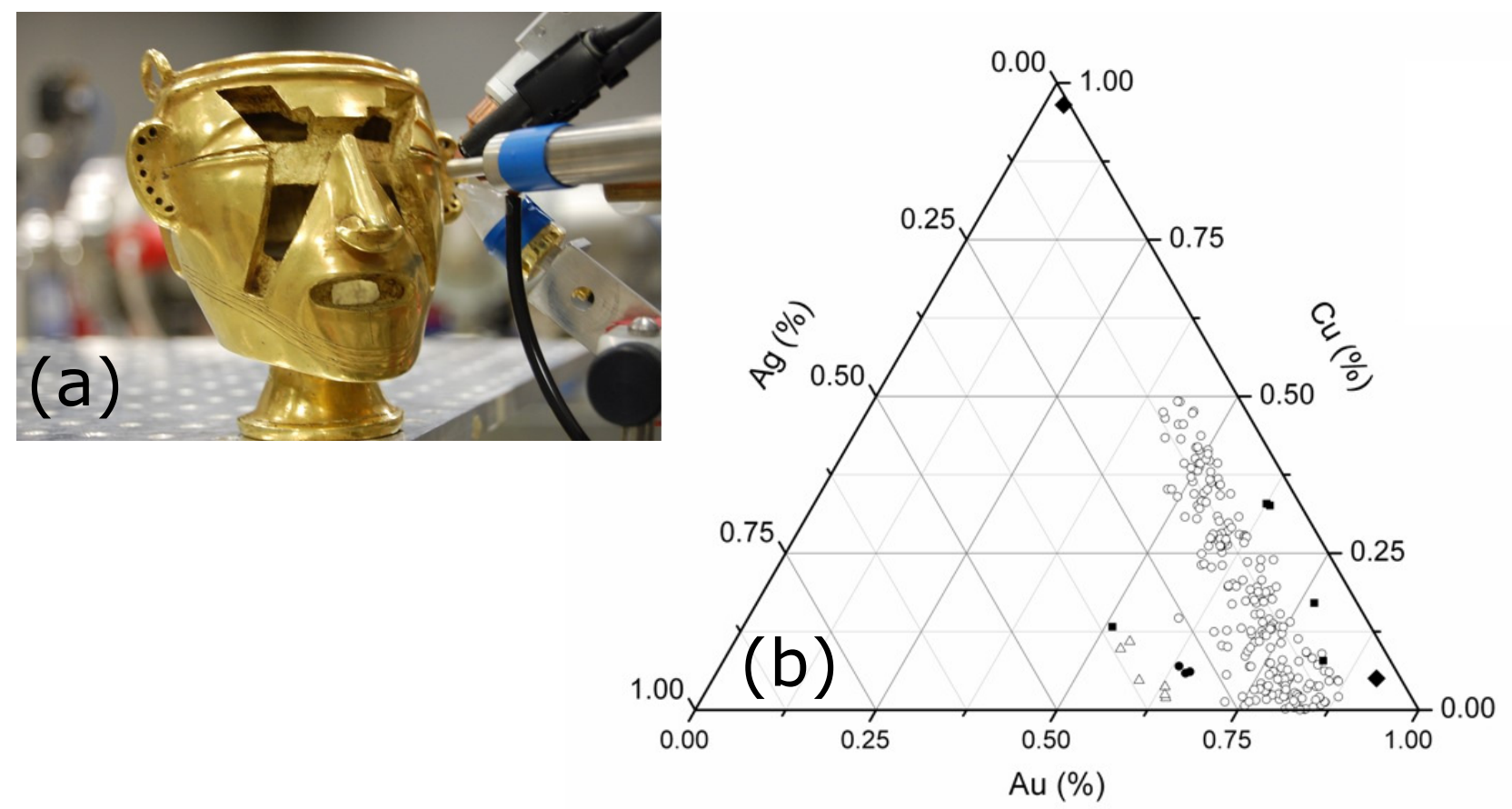

Fig. 6. (a) Quimbaya anthropomorphic vessel in the form of a man's head analysed at the external microbeam line. (b) Ternary $\mathrm{Au}$-Ag-Cu diagrams for 242 data points from 63 Quimbaya items. Thanks to the PIXE analysis of the alloys three main groups of objects were identified.

Figure 6 shows the representative IBA study of the Quimbaya treasure, devoted to determine the metal composition. A set of 63 pieces with anthropomorphic and phytomorphic vessels (Fig. 6a), helmets, headed pins, a crown, a whistle, nose rings, earrings, bells, bracelets, quite a variety of beads, micro-beads and zoomorphic and anthropomorphic pendants was analised. All of them are described in the literature as made up of tumbaga alloy with an enriched surface. IBA results showed that the whole collection is composed of a characteristic ternary Au-Ag-Cu alloy. As depicted in 
Figure $6 \mathrm{~b}$ the Quimbaya assemblage shows variable bulk compositions, comprising three main groups according to the silver content: one is characterized by a low $\mathrm{Ag}$ content $(<6 \%)$, the second one by a high $\mathrm{Ag}$ content $(27 \%)$, and the third and largest group features a broadly distributed composition with an intermediate roughly constant Ag content. Thanks to the sensitivity of PIXE, trace elements such as Fe and Zn were also identified, although this fact is probably related to inclusions of dust, not uniformly distributed over the porous surface or to modern cleaning products.

Besides these studies of important collections, other experimental works dealing with pieces of glass [73], minerals [74], and alloys from different archaeological sites [75-78] were also carried out at CMAM.

\section{Scientific prospects and future developments}

In parallel with the growing capabilities of the ion beam facility, the scientific strategies of CMAM has been adapted to the interests of the community and society too. The corner stone of the research developed in the Centre is the fabrication and analysis of Advanced materials. This research is continuously progressing and facing new technological challenges. One of the emerging projects that illustrates this is the investigation of materials for quantum applications. Some of the advanced materials under study respond to areas not yet explored at CMAM. In this sense, one ongoing project is devoted to the study of materials for electric propulsion in Space applications. This has been identified as a strategic technology for improving the European competitiveness in space operations and transportation. Accurate IBA studies of ceramic materials, in collaboration with the Advanced Thermal Devices company, are being carried out within the frame of the NEMESIS project (Novel Electride Material for Enhanced electrical propulSIon Solutions) of the Horizon 2020 European program.

Another important area where CMAM will continue working is Energy. In the last decade the ion beam facility has been a key part in experiments for future fusion reactors, especially within the framework of Technofusion project. One of the specific projects involves the ion irradiation of various materials for reactors (both metals and insulators). In order to improve the control of the irradiation with a quasi-continuous energy, a beam degrader has been developed and installed in the implantation beam line with a fast rotating carousel that supports several foils. In addition, a set-up for the irradiation of metals under stress has been also developed for future experiments. Besides, magnetooptical Kerr effect system will be installed for the in situ analysis of the magnetic changes and damage during the irradiations. All these improvements, together with the new fs-laser, will allow the investigation of ion-light-matter interactions, a field where CMAM has highlighted in the last years.

Another strategic line with a rising interest at CMAM is Health. During the last decades, radiation oncology has experienced a major scientific revolution with the discovery of the so-called FLASH effect [79], which consists of the reduction of the side effects of radiation in healthy tissue when doses are deposited in very high rates. Besides, protontherapy (PT) reduces the radiation dose received by healthy tissue surrounding the tumour, making it particularly suitable for paediatric patients or for tumours that cannot be treated surgically [80]. Therefore, it is expected that the biological properties of the high dose rates radiotherapy combined with the special precision of PT (FLASH-PT) improve the radiotherapy treatments reducing the normal injury after radiation.

Although CMAM is not designed for patient treatment, it can produce up to $10 \mathrm{MeV}$ proton beams and its unique characteristics (stable current, small beam size, precise energy) make it an ideal facility for preclinical research in the form of cell culture or small animal irradiation. Thus, the challenge in the near future is to contribute to the progress in the radiobiology investigations, taking advantage of CMAM as a developing infrastructure needed in biomedicine experiments with particle accelerators. Moreover, CMAM will also contribute to increase the knowledge and the control of the physical parameters that govern the biology of the FLASH effect (temporal structure of the beam, particle energy, and samples oxygenation level). To make it possible, CMAM has established a strong collaboration with the Complutense University of Madrid and the first PT centres in Spain: Quironsalud [81] and the Fundación Jiménez Díaz University Hospital [82].

One of the current activities aiming to contribute to on-line dosimetry in proton therapy is the development of a proof-of-concept use of double-sided Si strip detectors (DSSD) for medical imaging with the proton-CT technique by using proton beams. If successful, this will allow a more accurate treatment dose plans for PT. It has been proved that the amount of energy loss in the sample can be deduced and the image of the sample can be generated with this approach. Considering the energies at CMAM, the main goal is the analysis of two-dimensional samples profiting from the resolution given using the pixelization of the DSSDs. For proton-CT scans of 3D objects at the typical energies of PT (100-230 MeV), beam time at other facilities (KVI in Netherlands and CCB in Poland) has been approved. After testing the prototype and the different reconstruction algorithms, this proof-of-concept detector will be available for PT. 


\section{Conclusions}

During the lifetime of CMAM, the facility has provided beam time for hundreds of scientists from different fields, making IBA and IBMM accessible to a broad community. In the last years, several technical improvements have been incorporated to the pre-existing beam lines and experimental stations. As a result, nowadays more sophisticated experiments can be carried out at the six operative beam lines. Among these non-standard experiments we highlight the capabilities of CMAM to provide high-energy heavy ions and high-resolution microbeams.

Experiments with heavy ions can be extremely useful for some IBA analyses, such as ERDA-TOF, heavy ion PIXE, IL or STIM. Taking advantage of these methods, some of the common limitations in challenging samples (overlapping signals, low resolution, selectivity, etc.) can be overcome. Besides, the use of SHI for IBMM has demonstrated to be of great scientific interest. Many different materials have been modified for a wide range of applications, from optical waveguides and nanotrack formation, to amorphization and patterning of substrates. In addition, the availability of energies higher than in comparable similar facilities has prompted the studies of nuclear reactions of astrophysical interest, as well as proof-of-principle studies of proton images for PT facilities.

High-resolution microbeams are essential in studies demanding elemental mapping or non-destructive analysis. The internal microprobe at CMAM allows the characterization with resolutions in the $\mu$ m range, not only for protons but, remarkably, for other heavier ions too. This allows the analysis and modification of samples of biological and technological interest. The external microbeam can reach resolutions of $50 \mu \mathrm{m}$ for analysis requiring in-air samples. Singular archaeometry and cultural heritage studies have distinguished the activity of this beam line in the last years, although recent studies have driven the research towards other applications for PT.

The CMAM continues supplying ion beams and providing expertise and training for external users. In parallel with this service to the scientific community, CMAM has also prepared strategies to face the new challenges identified by the European Union. It is expected that some important research lines, linked to Space, Energy and Health applications continue and develop more in the next years.

\section{Acknowledgments}

We especially thank the effort of many people contributing to the development of CMAM in the last 18 years, including the technical, scientific, and administrative staff. We also thank to all the external users and scientists whom have contributed to the progress of research activities in the Centre. We acknowledge funding from EU COST Action CA17126, national projects ENE2016-80788-05-2-R, CTQ-2017-84309-C2-2-R, FPA2017-87568-P, and PID2019-104390BG-I00, PID2019-105156GB-I00, and local projects S2017/BMD-3888, TransNanoAvansens (P2018/NMT4349), TechnofusionIII (S2018/EMT-4437) from Comunidad Autónoma de Madrid. ARC acknowledges Ramón y Cajal program under contract RYC-2015-18047.

\section{References}

1. A. Sessler, E. Wilson, Engines of Discovery (World Scientific, New Jersey, 2007)

2. IAEA. Database of electrostatic accelerators. https://nucleus.iaea.org/sites/accelerators/Pages/ADB.aspx

3. M. Nastasi, J. Mayer, Ion Implantation and Synthesis of Materials (Springer, Berlin, 2010)

4. W. Wesch, E. Wendler, Ion Beam Modification of Solids (Springer, 2016)

5. T. Som, D. Kanjilal, Nanofabrication by Ion-Beam Sputtering (Jenny Stanford Publishing, 2012)

6. Y. Wang, M. Nastasi, Handbook Modern Ion Beam Materials Analysis (Materials Research Society, Warrendale, 2009)

7. C. Jeynes, J.L. Colaux, Analyst 141(21), 5944 (2016). DOI 10.1039/C6AN01167E

8. C. Jeynes, M. Bailey, N. Bright, M. Christopher, G. Grime, B. Jones, V. Palitsin, R. Webb, Nucl. Instrum. Methods Phys. Res. B 271, 107 (2012). DOI 10.1016/j.nimb.2011.09.020

9. A. Redondo-Cubero, V. Corregidor, L. Vázquez, L.C. Alves, Nucl. Instrum. Methods Phys. Res. B 348(Supplement C), 246 (2015). DOI 10.1016/j.nimb.2014.11.040

10. C. Jeynes, V. Palitsin, M. Kokkoris, A. Hamilton, G. Grime, Nucl. Instrum. Methods Phys. Res. B 465, 85 (2020). DOI 10.1016/j.nimb.2019.12.019

11. A. Zucchiatti, A. Redondo-Cubero, Nucl. Instrum. Methods Phys. Res. B 331, 48 (2014). DOI 10.1016/j.nimb.2014.02.013

12. A. Gottdang, D. Mous, R. Haitsma, Nucl. Instrum. Methods Phys. Res. B 190(1), 177 (2002). DOI 10.1016/S0168-583X(02) 00458-5

13. A. Climent-Font, F. Pászti, G. García, M. Fernández-Jiménez, F. Agulló, Nucl. Instrum. Methods Phys. Res. B 219-220, 400 (2004). DOI 10.1016/j.nimb.2004.01.090

14. D. Bachiller-Perea, A. Munoz-Martin, P. Corvisiero, D. Jimenez-Rey, V. Joco, A. Maira, A. Nakbi, A. Rodriguez, J. Narros, A. Zucchiatti, Energy Procedia 41, 57 (2013). DOI 10.1016/j.egypro.2013.09.007

15. D. Jamieson, Nucl. Instrum. Methods Phys. Res. B 136-138, 1 (1998). DOI 10.1016/S0168-583X(97)00657-5 
16. M. van den Putte, J. van den Brand, D. Jamieson, B. Rout, R. Szymanski, Nucl. Instrum. Methods Phys. Res. B 210, 21 (2003). DOI 10.1016/S0168-583X(03)01006-1

17. M.D. Ynsa, M.A. Ramos, N. Skukan, V. Torres-Costa, M. Jakšić, Nucl. Instrum. Methods Phys. Res. B 348, 174 (2015). DOI 10.1016/j.nimb.2014.11.036

18. M. Laitinen, M. Rossi, J. Julin, T. Sajavaara, Nucl. Instrum. Methods Phys. Res. B 337, 55 (2014). DOI 10.1016/j.nimb. 2014.07.001

19. O. Enguita, M. Fernández-Jiménez, G. García, A. Climent-Font, T. Calderón, G. Grime, Nucl. Instrum. Methods Phys. Res. B 219-220, 384 (2004). DOI 10.1016/j.nimb.2004.01.087

20. L.M. Fraile, J. Äystö, Nucl. Instrum. Methods Phys. Res. A 513(1), 287 (2003). DOI 10.1016/j.nima.2003.08.049

21. M. Carmona-Gallardo, B.S. Nara Singh, M.J.G. Borge, J.A. Briz, M. Cubero, B.R. Fulton, H. Fynbo, N. Gordillo, M. Hass, G. Haquin, A. Maira, E. Nácher, Y. Nir-El, V. Kumar, J. McGrath, A. Muñoz-Martín, A. Perea, V. Pesudo, G. Ribeiro, J. Sánchez del Rio, O. Tengblad, R. Yaniv, Z. Yungreis, Phys. Rev. C 86(3), 032801 (2012). DOI 10.1103/PhysRevC.86. 032801

22. M. Alcorta, M.J.G. Borge, M. Cubero, C.A. Diget, R. Domínguez-Reyes, L.M. Fraile, B.R. Fulton, H.O.U. Fynbo, D. Galaviz, S. Hyldegaard, H. Jeppesen, B. Jonson, O.S. Kirsebom, M. Madurga, A. Maira, A. Muñoz-Martín, T. Nilsson, G. Nyman, D. Obradors, A. Perea, K. Riisager, O. Tengblad, M. Turrion, Phys. Rev. C 86(6), 064306 (2012). DOI 10.1103/PhysRevC. 86.064306

23. J.G. Buijnsters, R. Gago, A. Redondo-Cubero, I. Jiménez, J. Appl. Phys. 112(9), 093502 (2012). DOI 10.1063/1.4764001

24. R.W. Smith, J. Plaza, D. Ghita, M. Sánchez, B.J. García, A. Muñoz-Martín, A. Climent-Font, Nucl. Instrum. Methods Phys. Res. B 266(8), 1450 (2008). DOI 10.1016/j.nimb.2008.01.024

25. W. Assmann, J. Davies, G. Dollinger, J. Forster, H. Huber, T. Reichelt, R. Siegele, Nucl. Instrum. Methods Phys. Res. B 118(1), 242 (1996). DOI 10.1016/0168-583X(95)01183-8

26. R. Escobar Galindo, N. Benito, D. Duday, G.G. Fuentes, N. Valle, P. Herrero, L. Vergara, V. Joco, O. Sanchez, A. Arranz, C. Palacio, J. Anal. At. Spectrom. 27(3), 390 (2012). DOI 10.1039/C2JA10296J

27. E. Salas, R.J. Jiménez Riobóo, J. Sánchez-Marcos, F. Jiménez-Villacorta, A. Muñoz-Martín, J.E. Prieto, V. Joco, C. Prieto, J. Appl. Phys. 114(21), 213508 (2013). DOI 10.1063/1.4837655

28. M. Gómez-Castaño, A. Redondo-Cubero, L. Vázquez, J.L. Pau, ACS Appl. Mater. Interfaces 8(42), 29163 (2016). DOI 10.1021/acsami.6b09805

29. M. Gómez-Castaño, J.L. Pau, A. Redondo-Cubero, CrystEngComm 20(26), 3666 (2018). DOI 10.1039/C8CE00390D

30. J.E. Prieto, A. Zucchiatti, P. Galán, P. Prieto, Nucl. Instrum. Methods Phys. Res. B 406, 167 (2017). DOI 10.1016/j.nimb. 2017.01.047

31. D. Jimenez-Rey, O. Peña-Rodríguez, J. Manzano-Santamaría, J. Olivares, A. Muñoz-Martin, A. Rivera, F. Agulló-López, Nucl. Instrum. Methods Phys. Res. B 286, 282 (2012). DOI 10.1016/j.nimb.2011.12.025

32. M.A. Ramos, J. Barzola-Quiquia, P. Esquinazi, A. Muñoz-Martin, A. Climent-Font, M. García-Hernández, Phys. Rev. B 81(21), 214404 (2010). DOI 10.1103/PhysRevB.81.214404

33. D. Martín y Marero, N. Gordillo, R. González-Arrabal, Phys. Rev. B 79(15), 155449 (2009). DOI 10.1103/PhysRevB.79. 155449

34. J. Olivares, G. García, F. Agulló-López, F. Agulló-Rueda, A. Kling, J. Soares, Appl. Phys. A 81(7), 1465 (2005). DOI $10.1007 / \mathrm{s} 00339-005-3237-\mathrm{x}$

35. J. Olivares, A. García-Navarro, G. García, F. Agulló-López, F. Agulló-Rueda, A. García-Cabañes, M. Carrascosa, J. Appl. Phys. 101(3), 033512 (2007). DOI 10.1063/1.2434801

36. A. García-Navarro, F. Agulló-López, J. Olivares, J. Lamela, F. Jaque, J. Appl. Phys. 103(9), 093540 (2008). DOI 10.1063/ 1.2912494

37. A. Rivera, J. Olivares, G. García, J.M. Cabrera, F. Agulló-Rueda, F. Agulló-López, Phys. Stat. Sol. (a) 206(6), 1109 (2009). DOI 10.1002/pssa.200824409

38. J. Manzano-Santamaría, J. Olivares, A. Rivera, O. Peña-Rodríguez, F. Agulló-López, Appl. Phys. Lett. 101(15), 154103 (2012). DOI 10.1063/1.4757886

39. O. Peña-Rodríguez, M. Crespillo, P. Díaz-Nuñez, J. Perlado, A. Rivera, J. Olivares, Opt. Mater. Express 6(3), 734 (2016). DOI 10.1364/OME.6.000734

40. O. Peña-Rodríguez, D. Jiménez-Rey, J. Manzano-Santamaría, J. Olivares, A. Muñoz, A. Rivera, F. Agulló-López, Appl. Phys. Express 5(1), 011101 (2011). DOI 10.1143/apex.5.011101

41. F.J. Sánchez, I. García-Cortés, J.F. Marco, D. Jiménez-Rey, A. Maira, J. Castellanos, R. Vila, Á. Ibarra, Nuclear Materials and Energy 9, 476 (2016). DOI 10.1016/j.nme.2016.05.010

42. I. García-Cortés, T. Leguey, F. Sánchez, A. Maira, A. Moroño, P. Muñoz, M. Scepanovic, J.F. Marco, J. Nucl. Mater. 517, 138 (2019). DOI 10.1016/j.jnucmat.2019.02.009

43. O. Peña-Rodríguez, A. Prada, J. Olivares, A. Oliver, L. Rodríguez-Fernández, H.G. Silva-Pereyra, E. Bringa, J.M. Perlado, A. Rivera, Sci. Rep. 7(1), 922 (2017). DOI 10.1038/s41598-017-01145-0

44. A. Egaña, V. Tormo-Márquez, A. Torrente, J. Muñoz-Santiuste, J. Olivares, M. Tardío, Nucl. Instrum. Methods Phys. Res. B 435, 152 (2018). DOI 10.1016/j.nimb.2017.11.010

45. G. García, M. Díaz-Híjar, V. Tormo-Márquez, I. Preda, O. Peña-Rodríguez, J. Olivares, Diam. Relat. Mater. 58, 226 (2015). DOI 10.1016/j.diamond.2015.08.014

46. G. García, I. Preda, M. Díaz-Híjar, V. Tormo-Márquez, O. Peña-Rodríguez, J. Olivares, F. Bosia, N. Pugno, F. Picollo, L. Giuntini, A. Sordini, P. Olivero, L. López-Mir, C. Ocal, Diam. Relat. Mater. 69, 1 (2016). DOI 10.1016/j.diamond.2016. 06.015 
47. M.D. Ynsa, F. Agulló-Rueda, N. Gordillo, A. Maira, D. Moreno-Cerrada, M.A. Ramos, Nucl. Instrum. Methods Phys. Res. B 404, 207 (2017). DOI 10.1016/j.nimb.2017.01.052

48. F. Agulló-Rueda, M.D. Ynsa, N. Gordillo, A. Maira, D. Moreno-Cerrada, M.A. Ramos, Diam. Relat. Mater. 72, 94 (2017). DOI 10.1016/j.diamond.2017.01.010

49. F. Agulló-Rueda, N. Gordillo, M.D. Ynsa, A. Maira, J. Cañas, M.A. Ramos, Carbon 123, 334 (2017). DOI 10.1016/j. carbon.2017.07.076

50. P. Aprà, J. Ripoll-Sau, J. Manzano-Santamaría, C. Munuera, J. Forneris, S. Ditalia Tchernij, P. Olivero, F. Picollo, E. Vittone, M. Ynsa, Diam. Relat. Mater. 104, 107770 (2020). DOI 10.1016/j.diamond.2020.107770

51. E. Punzón-Quijorna, V. Torres-Costa, M. Manso-Silván, R. Martín-Palma, A. Climent-Font, Nucl. Instrum. Methods Phys. Res. B 282, 25 (2012). DOI 10.1016/j.nimb.2011.08.040

52. E. Punzón-Quijorna, S. Kajari-Shröder, F. Agulló-Rueda, M. Manso Silván, R.J. Martín-Palma, P. Herrero Fernández, V. Torres-Costa, A. Climent-Font, Vacuum 138, 238 (2017). DOI 10.1016/j.vacuum.2016.10.011

53. J. Olivares, A. García-Navarro, G. García, A. Méndez, F. Agulló-López, A. García-Cabañes, M. Carrascosa, O. Caballero, Opt. Lett. 32(17), 2587 (2007). DOI 10.1364/OL.32.002587

54. O. Caballero-Calero, A. García-Cabañes, M. Carrascosa, V. Bermúdez, M. Crespillo, J. Olivares, Ferroelectrics 390(1), 29 (2009). DOI 10.1080/00150190902993424

55. M. Jubera, A. García-Cabañes, J. Olivares, A. Alcazar, M. Carrascosa, Opt. Lett. 39(3), 649 (2014). DOI 10.1364/OL.39. 000649

56. A. García-Navarro, J. Olivares, G. García, F. Agulló-López, S. García-Blanco, C. Merchant, J.S. Aitchison, Nucl. Instrum. Methods Phys. Res. B 249(1), 177 (2006). DOI 10.1016/j.nimb.2006.03.108

57. C.A. Merchant, P. Scrutton, S. Garcia-Blanco, C. Hnatovsky, R.S. Taylor, A. Garcia-Navarro, G. Garcia, F. Agullo-Lopez, J. Olivares, A.S. Helmy, J.S. Aitchison, IEEE J. Quantum Electon. 45(4), 373 (2009). DOI 10.1109/JQE.2009.2013216

58. R. Frentrop, I. Subbotin, F. Segerink, R. Keim, V. Tormo-Marquez, J. Olivares, K. Shcherbachev, S. Yakunin, I. Makhotkin, S.M. Garcia-Blanco, Opt. Mater. Express 9(12), 4796 (2019). DOI 10.1364/OME.9.004796

59. S.M. Martinussen, R.N. Frentrop, M. Dijkstra, F. Segerink, V. Tormo-Márquez, J. Olivares, S.M. Garcia-Blanco, Opt. Mater. Express 9(8), 3371 (2019). DOI 10.1364/OME.9.003371

60. V. Tormo-Marquez, M. Díaz-Hijar, M. Carrascosa, V.Y. Shur, J. Olivares, Opt. Express 27(6), 8696 (2019). DOI 10.1364/ OE. 27.008696

61. J. Manzano, J. Olivares, F. Agulló-López, M. Crespillo, A. Moroño, E. Hodgson, Nucl. Instrum. Methods Phys. Res. B 268(19), 3147 (2010). DOI 10.1016/j.nimb.2010.05.075

62. J. Olivares, A. García-Navarro, G. García, A. Mýndez, F. Agulló-López, Appl. Phys. Lett. 89(7), 071923 (2006). DOI $10.1063 / 1.2236221$

63. M.L. Crespillo, O. Caballero-Calero, V. Joco, A. Rivera, P. Herrero, J. Olivares, F. Agulló-López, Appl. Phys. A 104(4), 1143 (2011). DOI 10.1007/s00339-011-6391-3

64. Á.R. Páramo, F. Sordo, D. Garoz, O. Peña-Rodríguez, A. Prada, J. Olivares, M. Crespillo, J. Perlado, A. Rivera, Nucl. Instrum. Methods Phys. Res. B 352, 145 (2015). DOI 10.1016/j.nimb.2014.12.073

65. T. Pinheiro, M. Ynsa, L. Alves, P. Teixeira, J. Ferreira, P. Filipe, Nucl. Instrum. Methods Phys. Res. B 348, 119 (2015). DOI 10.1016/j.nimb.2014.11.042

66. A. Redondo-Cubero, M. Ynsa, M. Romero, L. Alves, E. Muñoz, Nucl. Instrum. Methods Phys. Res. B 306, 212 (2013). DOI 10.1016/j.nimb.2012.12.030

67. H. Liang, Z. Dang, J. Wu, J. van Kan, S. Qureshi, M. Ynsa, V. Torres-Costa, A. Maira, T. Venkatesan, M. Breese, Nucl. Instrum. Methods Phys. Res. B 394, 1 (2017). DOI 10.1016/j.nimb.2016.12.025

68. J.R. Bird, P. Duerden, D.J. Wilson, Ion Beam Techniques in Archaeology and the Arts (Harwood Academic Publishers, Chur, Switzerland, 1983)

69. A. Zucchiatti, A. Climent Font, P.C. Gutierrez Neira, A. Perea, P. Fernandez Esquivel, S. Rovira Llorens, J.L. Ruvalcaba Sil, A. Verde, Nucl. Instrum. Methods Phys. Res. B 332, 160 (2014). DOI 10.1016/j.nimb.2014.02.052

70. A. Perea, P. Gutiérrez-Neira, A. Climent-Font, P. Fernández-Esquivel, S. Rovira-Llorens, J. Ruvalcaba-Sil, A. Verde, A. Zucchiatti, Journal of Archaeological Science 40(5), 2326 (2013). DOI 10.1016/j.jas.2012.12.033

71. A. Perea, A. Climent-Font, M. Fernández-Jiménez, O. Enguita, P. Gutiérrez, S. Calusi, A. Migliori, I. Montero, Nucl. Instrum. Methods Phys. Res. B 249(1), 638 (2006). DOI 10.1016/j.nimb.2006.03.071

72. A. Zucchiatti, A.C. Font, M.C. Galassi, Stud. Conserv. 57(3), 131 (2012). DOI 10.1179/2047058412Y.0000000003

73. A. Zucchiatti, A. Climent-Font, P. Gutiérrez-Neira, I. Montero-Ruiz, J. Fuenlabrada, C. Galindo, J. Archaeol. Sci. Rep. 19, 439 (2018). DOI 10.1016/j.jasrep.2018.03.015

74. P.C. Gutiérrez, M.D. Ynsa, A. Climent-Font, T. Calligaro, Nucl. Instrum. Methods Phys. Res. B 268(11), 2038 (2010). DOI 10.1016/j.nimb.2010.02.053

75. P.C. Gutiérrez Neira, A. Zucchiatti, I. Montero-Ruiz, R. Vilaça, C. Bottaini, M. Gener, A. Climent-Font, Nucl. Instrum. Methods Phys. Res. B 269(24), 3082 (2011). DOI 10.1016/j.nimb.2011.04.072

76. A. Zucchiatti, P.C. Gutiérrez Neira, A. Climent-Font, C. Escudero, M. Barrera, Nucl. Instrum. Methods Phys. Res. B 269(24), 3115 (2011). DOI 10.1016/j.nimb.2011.04.084

77. M.D. Ynsa, J. Chamón, P. Gutiérrez, I. Gomez-Morilla, O. Enguita, A.I. Pardo, M. Arroyo, J. Barrio, M. Ferretti, A. Climent-Font, Appl. Phys. A 92(1), 235 (2008). DOI 10.1007/s00339-008-4497-z

78. A. Perea, P.C. Gutiérrez-Neira, A. Climent-Font, Mediterr. Archaeol. Archaeom. 18, 1 (2018). DOI 10.5281/ZENODO. 1461657 
79. A. Mazal, Y. Prezado, C. Ares, L. de Marzi, A. Patriarca, R. Miralbell, V. Favaudon, BJR 93(1107), 20190807 (2020). DOI $10.1259 /$ bjr.20190807

80. A.R. Smith, Phys. Med. Biol. 51(13), R491 (2006). DOI 10.1088/0031-9155/51/13/r26

81. QuironSalud. Centro de protonterapia. www.quironsalud.es/es/protonterapia

82. F.J. Díaz. Instituto de Investigación Sanitaria. www.fjd.es 